\title{
Development of a one-item version of the Orofacial Esthetic Scale
}

\author{
Stephanie Bela Andela ${ }^{1} \cdot$ Ragna Lamprecht ${ }^{*} \cdot$ Mike T. John $^{2} \cdot$ Swaha Pattanaik $^{2} \cdot$ Daniel R. Reissmann $^{1}$
}

Received: 30 March 2021 / Accepted: 22 June 2021 / Published online: 6 July 2021

(c) The Author(s) 2021

\begin{abstract}
Objectives Orofacial appearance is increasingly recognized as an important dental patient-reported outcome making instrument development and refinement efforts to measure the outcome better necessary. The aim of this study was to derive a one-item version of the Orofacial Esthetic Scale (OES).

Materials and methods OES data were collected from a consecutive sample of a total of 2113 adult English- or Spanishspeaking dental patients from HealthPartners dental clinic in Minnesota. Participants with missing data were excluded and analysis were performed using data from 2012 participants. Orofacial appearance was assessed with the English and the Spanish language version of the OES. Linear regression analysis was performed, with the OES item 8 ("Overall, how do you feel about the appearance of your face, your mouth, and your teeth?") as the predictor variable and the OES summary score as the criterion variable, to calculate the adjusted coefficients of determination $\left(\mathrm{R}^{2}\right)$.

Results The value of adjusted $\mathrm{R}^{2}$ was 0.83 , indicating that the OES item 8 score explained about $83 \%$ of the variance of the OES summary score. The difference in $\mathrm{R}^{2}$ scores between the two language groups was negligible.

Conclusion The OES item 8 can be used for the one-item OES (OES-1). It is a psychometrically sound instrument for measuring orofacial appearance.

Clinical relevance Due to its easy application and sufficient psychometric properties, the OES- 1 can be used effectively as an alternative to longer OES instruments in all areas of dental practice and research.
\end{abstract}

Keywords Orofacial appearance $\cdot$ Orofacial esthetics $\cdot$ Dental patient-reported outcome $\cdot$ Dental patient-reported outcome measures $\cdot$ Short instrument $\cdot$ Instrument development

\section{Introduction}

The patient perspective is fundamental for evidence-based dentistry [1,2]. Orofacial appearance (OA) is increasingly considered to be one of the most important patient-reported outcomes (PROs) in dentistry. It is one of the main reasons for patients to pursue dental treatments [3], especially orthodontic treatments $[4,5]$. Previous studies have recognized

Stephanie Bela Andela and Ragna Lamprecht contributed equally to this publication and should be considered as joint first authors.

\section{Daniel R. Reissmann}

d.reissmann@uke.de

1 Department of Prosthetic Dentistry, Center for Dental and Oral Medicine, University Medical Center HamburgEppendorf, Martinistr. 52, 20246 Hamburg, Germany

2 Department of Diagnostic and Biological Sciences, School of Dentistry, University of Minnesota, Minneapolis, MN, USA
$\mathrm{OA}$ as one of the dimensions of oral health-related quality of life (OHRQoL) [6-8]. Furthermore, OA plays an important role in determining physical attractiveness of an individual [9] and impacts self-confidence and social interactions [10-13]. For instance, previous studies showed patients with misaligned teeth (malocclusion) and other dental abnormalities were perceived as less intelligent, less beautiful, and even socially disadvantaged [14-17]. As OA is an important PRO, a simple tool is needed to evaluate the impact of dental interventions on perceived OA. Furthermore, such a tool or instrument should also be applicable in large epidemiological studies. Accordingly, a short instrument is required minimizing burden for participants and simultaneously not adding too many items to the questionnaire battery, which might result in higher probability of missing data and non-response.

Currently, OA can be assessed by several instruments $[18,19]$, including the Oral Health Impact Profile (OHIP) [20], the most widely used multidimensional instrument 
for determining OHRQoL. OA can be assessed by various number of items ranging from six items of the original 49-item OHIP to one item for the 5-item short version [6, 7]. However, even the long OHIP does not seem to capture all aspects of OA [21]. Therefore, specific instruments to assess OA were developed. The Orofacial Esthetic Scale (OES) is a unidimensional 8-item instrument with sufficient validity and reliability, initially developed to comprehensively assess OA in prosthodontic patients [22, 23]. It has been translated and validated in several languages, and normative values for the general population are provided [24-30]. Although OES-8 is not a lengthy instrument and does not substantially burden respondents, yet a one-item questionnaire will further reduce costs and burden and expand its application to several settings. A one-item OES could increase research efficiency, facilitate application in a larger study framework, and increase patient compliance.

Such an approach using a global rating has appeal. That is, patients can consider all relevant aspects of the construct to be measured, can ignore aspects that are not relevant to them, and can differently weight the impact of relevant aspects according to their perception when responding to the global rating [31]. Single, global questions have in fact long been used in population surveys to measure general health status, quality of life (QoL), and health-related quality of life (HRQoL) [32-34]. The development of short versions is also a current trend for dental patient-reported outcome measures (dPROMs). One example in dentistry is the 5-item OHIP (OHIP-5) that is already validated in German [35], English [36], and Spanish [37]. This short version collects about $90 \%$ of the information from the original 49 -item version, demonstrating its capabilities as a valuable tool for evaluating OHRQoL [35]. OHIP-5 provides the basis for the assumption that short versions are able to achieve comparable valid and reliable results despite reduction of the item pool. As an alternative, a single item dPROM would be even more promising.

Therefore, this study aimed to develop and validate a oneitem OES.

\section{Methods}

\section{Subjects, study design, and setting}

In this cross-sectional study, a sample of 2113 English- and Spanish-speaking adult dental patients who had scheduled a dental appointment at HealthPartners dental clinics in MN, USA, were approached to participate in the study and were consecutively recruited from July 2014 to April 2016. From the initial sample, only patients with sufficient information to characterize the construct were included in the final analysis $(N=2012)$.
Questionnaires were sent to participants, who filled in the questionnaire at home and sent it back to the HealthPartners Institute. For more information on sampling, see also Reissmann et al. [29] and Simancas-Pallares et al. [30].

This research was conducted in accordance with accepted ethical standards for human-subject research practice, undergoing review and approval by the Institutional Review Board of the HealthPartners Institute in Minneapolis, MN (registration number A11-136). Informed consent was obtained from all participants prior to their enrollment.

\section{The Orofacial Esthetic Scale}

Details of the development of OES have been published elsewhere [22, 23] and are briefly summarized here. We applied the English and the Spanish-language OES versions that were previously validated in the population of the current study $[29,30]$. The OES consists of seven items addressing patients' perceptions of specific esthetic components (i.e., appearance of face, mouth, teeth, and tooth replacement) and one item for the overall impression (item 8: "Overall, how do you feel about the appearance of your face, your mouth, and your teeth?"). The response format used is an 11-point rating scale, ranging from 0 ("very dissatisfied") to 10 ("very satisfied"). Scores of items 1 through 7 can be summed up to form an OES summary score that can range from 0 through 70 points, with higher scores representing better esthetics. Since item 8 represents an overall impression and no specific esthetic component, it was deemed a candidate to serve as one-item OES.

\section{Data analyses}

Participants' socio-demographic characteristics and OES item and summary scores are presented using measures for central tendency (means) and variability (standard deviation; $\mathrm{SD})$ for continuous measures, and frequencies and proportions for categorical measures. To ensure both language subgroups (English and Spanish) were comparable and could be analyzed collectively as one sample, subgroup characteristics were compared to test for statistically significant differences using two-sample t-test for continuous data (age and OES scores) and chi-squared test for categorical data (gender).

Linear regression analysis was performed to assess whether OES item 8 can be used for the one-item OES (OES-1). OES item 8 was used as the predictor variable and the OES summary score was used as the criterion variable for the linear regression model. Adjusted $\mathrm{R}^{2}$ was interpreted in terms of how much variance in OES summary score could be explained by OES item 8 . Since there is no commonly accepted guideline for judgment of $\mathrm{R}^{2}$ values available, and 
an acceptable level depends on the research context, for this study, we considered values of at least 0.75 as satisfactory. As additional sensitivity analysis, regression models were calculated for each language subgroup separately.

All eight OES items were complete in 1931 (91.3\%) participants. Only 595 missing answers were observed in 184 participants. For participants with one item with missing information in OES items 1 through 7, scores for these items were replaced by the median of the remaining items within a participant containing sufficient information. All participants with more than one item with missing information in OES items 1 through 7 and all participants with missing answers for item 8 were excluded from analyses.

All statistical analyses were performed using the statistical software package STATA/MP (Stata Statistical Software: Release 14.2. StataCorp LP, College Station, TX), with the probability threshold of a type I error set at 0.05 .

\section{Results}

\section{Characteristics of participants}

Participants were on average 54.5 years of age (Table 1). However, participants from the Spanish-speaking subgroup were on average about 14 years younger than those from the English-speaking subgroup $(p<0.001)$. Slightly more than half of the participants $(60 \%)$ were female with no statistically significant difference between groups ( $p=0.834$ ).

Mean OES scores for the individual items 1 to 7 in all participants ranged from 5.9 (item 6 - tooth color) to 7.7 points (item 1 - face, item 2 - profile; Table 1). Mean OES summary score was 48.8 and item 8 mean was 7.0 points. There were no statistically significant differences between the two language groups with regard to the individual item scores and the mean scores of OES (all $p>0.05$ ).
Table 1 Socio-demographic characteristics and OES scores for all participants and stratified by language-subgroups with statistical significance of between-group differences
Table 2 Linear regression models characterizing the relationship between OES item 8 and OES summary score in all participants and in language subgroups

\begin{tabular}{lllll}
\hline & $\begin{array}{l}\text { All } \\
n=2012\end{array}$ & $\begin{array}{l}\text { English } \\
n=1702\end{array}$ & $\begin{array}{l}\text { Spanish } \\
n=310\end{array}$ & $\begin{array}{l}\text { Statistical } \\
\text { signifi- } \\
\text { cance } \\
P \text {-value }\end{array}$ \\
& Mean (SD) or $n(\%)$ & & \\
& & & & \\
\hline Socio-demographic characteristics & & & & \\
Age (years) & $54.5(16.1)$ & $56.7(15.8)$ & $42.6(12.1)$ & 0.001 \\
Gender (woman) & $1205(59.9)$ & $1021(60.0)$ & $184(59.4)$ & 0.834 \\
OES scores & & & & \\
Item 1 (face) & $7.7(2.7)$ & $7.7(2.7)$ & $7.6(3.1)$ & 0.618 \\
Item 2 (profile) & $7.7(2.7)$ & $7.8(2.7)$ & $7.5(3.2)$ & 0.078 \\
Item 3 (mouth) & $6.9(3.1)$ & $6.9(3.1)$ & $6.9(3.3)$ & 0.674 \\
Item 4 (tooth alignment) & $6.6(3.3)$ & $6.6(3.2)$ & $6.5(3.5)$ & 0.535 \\
Item 5 (tooth shape) & $6.8(3.0)$ & $6.9(3.0)$ & $6.8(3.3)$ & 0.591 \\
Item 6 (tooth color) & $5.9(3.1)$ & $5.9(3.0)$ & $6.1(3.2)$ & 0.253 \\
Item 7 (gingiva) & $7.2(3.0)$ & $7.2(2.9)$ & $7.1(3.3)$ & 0.507 \\
Summary score & $48.8(18.2)$ & $48.9(17.8)$ & $48.5(20.1)$ & 0.700 \\
Item 8 (overall impression) & $7.0(2.9)$ & $7.0(2.8)$ & $7.3(3.0)$ & 0.095 \\
\hline
\end{tabular}

\begin{tabular}{|c|c|c|c|c|c|c|}
\hline Sample & Predictor variable & Criterion variable & Coefficient & $95 \% \mathrm{CI}$ & P-value & Adj. $R^{2}$ \\
\hline \multicolumn{7}{|c|}{ All participants } \\
\hline & OES item 8 & OES summary score & 5.8 & $5.7-5.9$ & $<0.001$ & 0.83 \\
\hline \multicolumn{7}{|c|}{ English-language participants } \\
\hline & OES item 8 & OES summary score & 5.8 & $5.6-5.9$ & $<0.001$ & 0.84 \\
\hline \multicolumn{7}{|c|}{ Spanish-language participants } \\
\hline & OES item 8 & OES summary score & 6.1 & $5.8-6.4$ & $<0.001$ & 0.82 \\
\hline
\end{tabular}




\section{OES item 8 (OES-1) as predictor for OES summary score}

The regression coefficient of 5.8 in the linear regression analysis indicates a 1-point difference of the OES item 8 score was related with a difference in OES summary score of 5.8 points (Table 2). The adjusted $\mathrm{R}^{2}$ of 0.83 in the model with all participants suggested that about $83 \%$ of variance in OES summary scores could be explained by OES item 8 score. The sensitivity analysis did not reveal any substantial differences in findings between the language groups with respect to regression coefficient and adjusted $R^{2}$ (Table 2).

\section{Discussion}

This is the first study to develop and validate a one-item OES. The findings of this study indicate that OES- 1 is a valid instrument to assess perceived OA.

Our results suggest that OES-1 sufficiently captures the OA construct even when compared across two language groups. The "overall impression of OA" item is a relevant and comprehensive indicator to measure OA in general and can replace the seven items of OES to produce a robust single-item scale. The $\mathrm{R}^{2}$ value indicates a "good model fit" as well as the ability of OES-1 to assess about $83 \%$ of the information of the original 8-item version, proving its suitability for accurately predicting perceived OA in general with good accuracy.

Our findings are comparable with those of other studies that aimed at developing shorter versions of dPROMs. However, several studies only performed correlation analyses and reported $r$-values. For example, a study on dental anxiety indicated that the scores of a single item were highly correlated with the original summary score $(r=0.77)$ [38]. Furthermore, the Swedish 14-item and 5 -item short form of the OHIP (OHIP-S14 and OHIPS5) correlated highly with the 49-item OHIP ( $r \geq 0.97$ for OHIP-S14, $r \geq 0.92$ for OHIP-S5) [39, 40]. Also, the Spanish language 5-item OHIP (OHIP-Sp5) summary scores showed "very large" effect $(r=0.95)$ in correlation with OHIP-Sp14 as well as with OHIP-Sp49 [37]. Nevertheless, in many cases, the coefficient of determination $\mathrm{R}^{2}$ is simply the square of the correlation coefficient $r$, i.e., $r=0.95$ would correspond to $\mathrm{R}^{2}=0.90$, demonstrating our findings do not differ substantially from those of Swedish and Spanish OHIP short forms. One study on German version of OHIP utilizing the same statistical methodology as in our study proved successfully that a 5-item version performed well in predicting summary scores of long OHIP version even in two different populations [35]. Adjusted $\mathrm{R}^{2}$ was 0.88 for the general population participants and 0.82 for temporomandibular disorders (TMD) patients, which is not too different from our findings. In contrast, a longer OHIP short form with 14 questions accounted for $94 \%$ of variance of the 49-item version [41]. German OHIP short forms with 14 items [42, 43] and with 21 items [44] explained $91 \%$ and $96 \%$ of the variance of the 49 -item version, respectively. But it is not surprising that instruments with more items cover more information of the original instrument than shorter versions. Therefore, these findings do not question our findings. Accordingly, OES-1 performed similar to other abbreviated dPROMs.

Our study has several strengths. Most importantly, the study investigated regular dental patients - a highly relevant target population for the assessment of $\mathrm{OA}$ - using a large sample $(n=2012)$ ensuring sufficient statistical power and precise estimations. The diversity of the population ensures high generalisability of findings and facilitates implementation in most research settings. Moreover, OES- 1 is derived from the existing OES-8, which has already proven itself in terms of validity and reliability [22]. We used a commonly applied method for imputation of missing data whilst taking into account that a person median imputation leads to the most accurate recovery and lowest bias across most conditions [45]. Furthermore, two different language versions of OES were used in the analysis. A recent study pooling OES data from Englishand Spanish-speaking patients supported absence of differential item functioning across the two language versions [46]. Accordingly, this study suggests equivalence between the two language versions for OES-1 in terms of intercultural use. This increases comparability of the instrument with prospects for successful transferability to other language versions of OES-1. Possible limitations of our study are missing information on income, place of residence, or educational status, since it is known that socioeconomic differences potentially affect patient reported OA [47, 48]. Nevertheless, we assume that the large sample size and the inclusion of the entire population from various social strata have eliminated this potential drawback.

OES-1 is a very short and easy-to-apply questionnaire, suitable to measure the entire construct of OA in general and dental patient populations when time and resources are limited. Its brevity and easy application make the one-item OES a pragmatic and timesaving tool for large epidemiological studies, national health surveys, or routine dental practice where a multi-item OES questionnaire is not feasible. Historically, multi-item instruments were used more commonly and single-item instruments in comparison were assumed to be less reliable and valid, and more limited. Today, researchers advocate the use of single-item measures especially in clinical settings as they are less time consuming, reduce respondent burden, and costs of data collection [49]. These benefits make single-item measures easily applicable in nonclinical community settings such as mobile dental clinics. 
Even though multi-item instruments are better suited for complex constructs and can be more discriminating, they are also time-taking and can possibly lead to response errors [50].

The current study findings show that OES-1 is a practical, concise, and highly reliable measure of OA. Having said that, further testing of its validity and reliability in different settings and populations is needed. OES- 1 represents a promising alternative to OES- 8 and its convenient application will encourage increased application among dental researchers and providers. It can be used as a standardized global measure to monitor and evaluate treatment effectiveness. This enables dentists and patients to benefit from the results in the shortest possible time and engage in shared treatment decision-making. Having two OES instruments with different lengths would enable the measurement of $\mathrm{OA}$ in almost all research and clinical settings. The ease of use will also help with medical and dental interprofessional collaboration. A one-item dPROM such as OES- 1 can contribute to effective communications with patients about expected treatment results [51]. It also furthers value-based oral health care [52] as it expedites the data collection and sharing process, leaving more time for dental care teams to engage in reflective learning and patient education. It can easily be used in resource limited settings and within largescale surveys to allow cross-country comparisons.

The study demonstrated that OES- 1 adequately captures the construct of OA. This provides a conceptually appealing and pragmatic opportunity that can be used in large epidemiological studies as well as in clinical trials and routine dental care. OES-1 paves way for other concise patient-centered outcome measures, which would help advance evidencebased dental practice.

Funding Open Access funding enabled and organized by Projekt DEAL. Research reported in this publication was supported by the National Institute of Dental and Craniofacial Research of the National Institutes of Health, USA, under Award Number R01DE028059.

\section{Declarations}

Ethical approval All procedures performed in studies involving human participants were in accordance with the ethical standards of the institutional and/or national research committee and with the 1964 Helsinki declaration and its later amendments or comparable ethical standards.

Informed consent Informed consent was obtained from all individual participants included in the study.

Conflict of interest The authors declare no competing interests.

Open Access This article is licensed under a Creative Commons Attribution 4.0 International License, which permits use, sharing, adaptation, distribution and reproduction in any medium or format, as long as you give appropriate credit to the original author(s) and the source, provide a link to the Creative Commons licence, and indicate if changes were made. The images or other third party material in this article are included in the article's Creative Commons licence, unless indicated otherwise in a credit line to the material. If material is not included in the article's Creative Commons licence and your intended use is not permitted by statutory regulation or exceeds the permitted use, you will need to obtain permission directly from the copyright holder. To view a copy of this licence, visit http://creativecommons.org/licenses/by/4.0/.

\section{References}

1. Hua F (2019) Increasing the value of orthodontic research through the use of dental patient-reported outcomes. J Evid Based Dent Pract 19:99-105

2. Reissmann DR (2019) Dental patient-reported outcome measures are essential for evidence-based prosthetic dentistry. J Evid Based Dent Pract 19:1-6

3. John MT, Sekulic S, Bekes K et al (2020) Why patients visit dentists - a study in all World Health Organization regions. J Evid Based Dent Pract 20:101459

4. Hamdan AM, Singh V, Rock WP (2012) Assessment of the relationship between perceptions of dental aesthetics and demand for orthodontic treatment in 10-11 year old school children in Birmingham, UK. Community Dent Hlth 29:124-128

5. Pietila T, Pietila I (1996) Dental appearance and orthodontic services assessed by 15-16-year-old adolescents in eastern Finland. Community Dent Health 13:139-144

6. John MT, Reissmann DR, Feuerstahler L et al (2014) Exploratory factor analysis of the Oral Health Impact Profile. J Oral Rehabil 41:635-643

7. John MT, Feuerstahler L, Waller N et al (2014) Confirmatory factor analysis of the Oral Health Impact Profile. J Oral Rehabil 41:644-652

8. John MT (2020) Foundations of oral health-related quality of life. J Oral Rehabil. https://doi.org/10.1111/joor.13040.

9. Kershaw S, Newton JT, Williams DM (2008) The influence of tooth colour on the perceptions of personal characteristics among female dental patients: comparisons of unmodified, decayed and 'whitened' teeth. Br Dent J 204:E9 (discussion 256-257)

10. Patzer GL (1997) Improving self-esteem by improving physical attractiveness. J Esthet Dent 9:44-46

11. Henson ST, Lindauer SJ, Gardner WG, Shroff B, Tufekci E, Best AM (2011) Influence of dental esthetics on social perceptions of adolescents judged by peers. Am J Orthod Dentofacial Orthop 140:389-395

12. Eli I, Bar-Tal Y, Kostovetzki I (2001) At first glance: social meanings of dental appearance. J Public Health Dent 61:150-154

13. Langlois JH, Kalakanis L, Rubenstein AJ, Larson A, Hallam M, Smoot M (2000) Maxims or myths of beauty? A meta-analytic and theoretical review. Psychol Bull 126:390-423

14. Kerosuo H, Hausen H, Laine T, Shaw WC (1995) The influence of incisal malocclusion on the social attractiveness of young adults in Finland. Eur J Orthod 17:505-512

15. Sierwald I, John MT, Schierz O, Jost-Brinkmann PG, Reissmann DR (2015) Association of overjet and overbite with esthetic impairments of oral health-related quality of life. J Orofac Orthop 76:405-420

16. Nagarajan S, Pushpanjali K (2010) The relationship of malocclusion as assessed by the Dental Aesthetic Index (DAI) with perceptions of aesthetics, function, speech and treatment needs among 
14- to 15-year-old schoolchildren of Bangalore, India. Oral Health Prev Dent 8:221-228

17. Bernabé E, Flores-Mir C (2007) Influence of anterior occlusal characteristics on self-perceived dental appearance in young adults. Angle Orthod 77:831-836

18. Mittal H, John MT, Sekulic S, Theis-Mahon N, Rener-Sitar K (2019) Patient-reported outcome measures for adult dental patients: a systematic review. J Evid Based Dent Pract 19:53-70

19. Rener-Sitar K, John M, Truong V, Tambe S, Theis-Mahon N (2021) Systematic review of nonmalignant oral disease-specific dPROMs for adult patients. J Evid Based Dent Pr 21:101529

20. Slade GD, Spencer AJ (1994) Development and evaluation of the Oral Health Impact Profile. Community Dent Health 11:3-11

21. Mehl C, Kern M, Freitag-Wolf S, Wolfart M, Brunzel S, Wolfart S (2009) Does the Oral Health Impact Profile Questionnaire measure dental appearance? Int J Prosthodont 22:87-93

22. Larsson P, John MT, Nilner K, List T (2010) Reliability and validity of the Orofacial Esthetic Scale in prosthodontic patients. Int J Prosthodont 23:257-262

23. Larsson P, John MT, Nilner K, Bondemark L, List T (2010) Development of an Orofacial Esthetic Scale in prosthodontic patients. Int J Prosthodont 23:249-256

24. Zhao Y, He SL (2013) Development of the Chinese version of the Oro-facial Esthetic Scale. J Oral Rehabil 40:670-677

25. Persic S, Milardovic S, Mehulic K, Celebic A (2011) Psychometric properties of the Croatian version of the Orofacial Esthetic Scale and suggestions for modification. Int J Prosthodont 24:523-533

26. Bimbashi V, Celebic A, Staka G, Hoxha F, Persic S, Petricevic $N$ (2015) Psychometric properties of the Albanian version of the Orofacial Esthetic Scale: OES-ALB. BMC Oral Health 15:97

27. Larsson P, John MT, Nilner K, List T (2014) Normative values for the Oro-facial Esthetic Scale in Sweden. J Oral Rehabil 41:148-154

28. Reissmann DR, Benecke AW, Aarabi G, Sierwald I (2015) Development and validation of the German version of the Orofacial Esthetic Scale. Clin Oral Investig 19:1443-1450

29. Reissmann DR, John MT, Enstad CJ, Lenton PA, Sierwald I (2019) Measuring patients' orofacial appearance: validity and reliability of the English-language Orofacial Esthetic Scale. J Am Dent Assoc 150:278-286

30. Simancas-Pallares M, John MT, Prodduturu S, Rush WA, Enstad CJ, Lenton P (2018) Development, validity and reliability of the Orofacial Esthetic Scale - Spanish version. J Prosthodont Res 62:456-461

31. Fayers PM, Machin D (2007) Principles of measurement scales. In: Fayers PM, Machin D (eds) Book title, second edn. Wiley, West Sussex

32. Reissmann DR, Schierz O, Szentpetery AG, John MT (2011) Improved perceived general health is observed with prosthodontic treatment. J Dent 39:326-331

33. Gill TM, Feinstein AR (1994) A critical appraisal of the quality of quality-of-life measurements. JAMA 272:619-626

34. Subramanian U, Eckert G, Yeung A, Tierney WM (2007) A single health status question had important prognostic value among outpatients with chronic heart failure. J Clin Epidemiol 60:803-811

35. John MT, Miglioretti DL, LeResche L, Koepsell TD, Hujoel P, Micheelis W (2006) German short forms of the Oral Health Impact Profile. Community Dent Oral Epidemiol 34:277-288
36. Naik A, John MT, Kohli N, Self K, Flynn P (2016) Validation of the English-language version of 5-item Oral Health Impact Profile. J Prosthodont Res 60:85-91

37. Simancas-Pallares M, John MT, Enstad C, Lenton P (2020) The Spanish language 5-item Oral Health Impact Profile. Int Dent J 70:127-135

38. Viinikangas A, Lahti S, Yuan S, Pietila I, Freeman R, Humphris G (2007) Evaluating a single dental anxiety question in Finnish adults. Acta Odontol Scand 65:236-240

39. Baba K, Inukai M, John MT (2008) Feasibility of oral healthrelated quality of life assessment in prosthodontic patients using abbreviated Oral Health Impact Profile questionnaires. J Oral Rehabil 35:224-228

40. Larsson P, John MT, Hakeberg M, Nilner K, List T (2014) General population norms of the Swedish short forms of oral health impact profile. J Oral Rehabil 41:275-281

41. Slade GD (1997) Derivation and validation of a short-form oral health impact profile. Community Dent Oral 25:284-290

42. Slade GD (1997) Derivation and validation of a short-form oral health impact profile. Community Dent Oral Epidemiol $25: 284-290$

43. Locker D, Allen FP (2001) Developing short-form measures of oral health-related quality of life using the item-impact method. J Dent Res 80:1146-1146

44. John MT, Hujoel P, Miglioretti DL, LeResche L, Koepsell TD, Micheelis W (2004) Dimensions of oral-health-related quality of life. J Dent Res 83:956-960

45. Feuerstahler L, Waller N, John MT (2013) Imputation methods for not applicable (NA) responses on the OHIP. J Dent Res 92:2582

46. Pattanaik S, John MT, Chung S (2021) Assessment of differential item functioning across English and Spanish versions of the Orofacial Esthetic Scale. J Oral Rehabil 48:73-80

47. Mehl CJ, Harder S, Kern M, Wolfart S (2011) Patients' and dentists' perception of dental appearance. Clin Oral Investig 15:193-199

48. Rosing K, Christensen LB, Ozhayat EB (2019) Associations between tooth loss, prostheses and self-reported oral health, general health, socioeconomic position and satisfaction with life. J Oral Rehabil 46:1047-1054

49. McKenzie N, Marks I (1999) Quick rating of depressed mood in patients with anxiety disorders. Br J Psychiatry 174:266-269

50. Drolet AL, Morrison DG (2016) Do we really need multiple-item measures in service research? J Serv Res 3:196-204

51. Palaiologou A, Kotsakis GA (2020) Dentist-patient communication of treatment outcomes in periodontal practice: a need for dental patient-reported outcomes. J Evid Based Dent Pract 20:101443

52. Listl S (2019) Value-based oral health care: moving forward with dental patient-reported outcomes. J Evid Based Dent Pract 19:255-259

Publisher's note Springer Nature remains neutral with regard to jurisdictional claims in published maps and institutional affiliations. 